\title{
MODEL PERTANIAN BIOINDUSTRI BERBASIS INTEGRASI SAWIT-SAPI DI PROVINSI RIAU
}

\section{Oil Palm-Cow Integration Based Model of Agricultural Bioindustry in Riau Province}

\author{
Dahono, Ida Nuristina, Oni Ekalinda, Agussalim dan Taufik Hidayat \\ Balai Pengkajian Teknologi Pertanian Riau \\ Jln. Kaharuddin Nasution km 10 no.341. Pekanbaru \\ Email: ddahono@yahoo.co.id
}

\begin{abstract}
The palm bioindustry farming model in Riau Province aims to utilize all factors of production. It can be turned into other products that are managed into bioenergy, as well as free of waste by applying the principles of reducing, re-using, and recycling (reduce, reuse and recycle). The agriculturebioindustry model is expected to produce a healthy, sustainable environment, and can increase the income of palm farmers in the study area and increase the efficiency of the oil palm farming. The bioindustrial agriculture model activity was carried out in Tapung District, Kampar Regency, Riau Province. It was started from January 2018 until December 2018. The scope of activities is in the form of coordination with related agencies, collecting primary data, introducing technology with socialization events and seeing the performance of bioindustry activities. The results of the activity can be reported that Tapung sub-district has a land area of $739.21 \mathrm{~km}^{2}$ or $73.921 \mathrm{ha}$, and an oil palm area of 34,102 ha, annual midrib production of 748,000 midribs $(1,645,600 \mathrm{~kg} / \mathrm{year})$ with an average livestock feed needs $20 \mathrm{~kg} / \mathrm{day}$. It means that the Tapung sub-district can accommodate 228 animals in a year, out of 228 animals produce $1,140 \mathrm{~kg}$ of dry manure and produce 684 liters of urine per day, depending on the age and body weight of the livestock. However, all the byproducts from cattle the oil palm is still being used for their own business needs and not yet for commercial use. Their own needs are in the form of impacts on farmers' palm production from the activities. It can be concluded that the performance of the bioindustry produces in higher palm oil production compared to existing ones.
\end{abstract}

Keyword: Bioindustry model, oil palm and cow

\begin{abstract}
ABSTRAK
Model pertanian bioindustri sapi-sawit di Provinsi Riau bertujuan untuk memanfaatkan seluruh faktor produksi yang dapat dijadikan produk lain yang dikelola menjadi bioenergi, serta bebas limbah dengan menerapkan prinsip mengurangi, memanfaatkan kembali, dan mendaur ulang (reduce, reuse dan recycle). Model pertanian bioindustri diharapkan menghasilkan lingkungan yang sehat, dan berkelanjutan, serta dapat meningkatkan pendapatan petani sawit-sapi diwilayah kajian dan meningkatkan efisiensi usaha tani sapi-sawit. Kegiatan model pertanian bioindustri dilakukan di Kecamatan Tapung, Kabupaten Kampar, Provinsi Riau. Mulai Januari 2018 sampai dengan Desember 2018. Ruang lingkup kegiatan berupa koordinasi dengan instansi terkait, mengumpulkan data primer, pengenalan teknologi dengan acara sosialisasi dan melihat kinerja dari kegiatan bioindustri. Hasil kegiatan dapat dilaporkan bahwa Kecamatan Tapung memiliki luas lahan $\pm 739,21 \mathrm{~km}^{2}$ atau 73.921 ha, dan memiliki lahan sawit seluas 34.102 ha, produksi pelepah pertahun 748.000 pelepah (1.645.600 $\mathrm{kg} / \mathrm{tahun}$ ), rata-rata kebutuhan pakan ternak $20 \mathrm{~kg} / \mathrm{hari}$. Berarti kecamatan tapung dapat menampung ternak sebanyak 228 ekor dalam setahun, dari 228 ekor ternak menghasilkan kotoran sebanyak $1140 \mathrm{~kg}$ kotoran kering dan menghasilkan urin sebanyak 684 liter perhari tergantung kepada umur dan bobot badan dari ternak tersebut, namun semua produksi hasil samping dari sapi-sawit tersebut masih
\end{abstract}


digunakan untuk kebutuhan usaha mereka sendiri dan belum untuk dikomersilkan. Kebutuhan mereka sendiri berupa dampak terhadap produksi sawit petani, dari kegiatan dapat disimpulkan bahwa kinerja bioindustri menghasilkan produksi sawit lebih tinggi dibanding eksisting.

Kata Kunci: Model pertanian bioindustri, sawit-sapi

\section{PENDAHULUAN}

Pengembangan pertanian Indonesia pada masa mendatang harus memperhatikan berbagai aspek dan menerapkan teknologi yang tepat. Penerapan inovasi teknologi harus memperhatikan efisiensi produksi, keberlanjutan sistim usahatani, dan lingkungan (Masganti, 2013). Melalui Strategi Induk Pembangunan Pertanian (SIPP) tahun 2013-2045, pembangunan pertanian Indonesia diarahkan pada pertanian bioindustri berkelanjutan (Biro Perencanaan, 2013). Visi pembangunan pertanian Indonesia hingga tahun 2045 adalah : "Terwujudnya sistim pertanian bioindustri berkelanjutan yang menghasilkan beragam pangan sehat dan produk bernilai tambah tinggi dari sumberdaya hayati pertanian dan kelautan tropika"(Biro perencanaan 2013).

Pengembangan pertanian bioindustri merupakan pembangunan pertanian berkelanjutan. Oleh karena itu, pertanian bioindustri mengandung beberapa prinsip dasar seperti berkelanjutan, berbasis masyarakat, lingkungan alam, pelaku agribisnis, berorientasi pengembangan usaha pertanian rakyat, serta berbasis sumberdaya lokal (Biro Perencanaan, 2013).

Luas lahan Perkebunan Kelapa Sawit di Indonesia pada tahun 2017 tercatat 12.307.677 ha, yang dikelola oleh perkebunan besar milik negara dan perkebunan besar milik swasta dan perkebunan rakyat, sebanyak $20.26 \%$ atau \pm 2.493.176 ha terdapat di Provinsi Riau (Ditjenbun, 2017). Menurut laporan Disbun Provinsi Riau (2013), perkebunan kelapa sawit yang telah menghasilkan (TM) banyak diusahakan oleh perkebunan rakyat, yakni sekitar $(53,35 \%)$, diikuti perkebunan besar swasta (PBS), sekitar 42,55\% dan sisanya dari perkebunan besar negara $(\mathrm{PBN})$. Akan tetapi produktivitas perkebunan rakyat lebih rendah dari PBS maupun PBN. Lokasi terluas terdapat di Kabupaten
Kampar (165.869 ha), Siak (163.380 ha), Rokan Hilir (145.769 ha), Rokan Hulu (140.135 ha), dan Pelalawan (111.568 ha).

Kelapa sawit, khususnya pelepahnya berpotensi besar dimanfaatkan sebagai pakan ternak sapi karena mengandung protein kasar sekitar 15\% (Paulian, 2009). Dalam satu tahun, kelapa sawit dapat menghasilkan 22 pelepah, dimana satu pelepah beratnya sekitar $7 \mathrm{~kg}$, sehingga jika dalam satu hektar terdapat 138 pohon kelapa sawit, maka dalam satu tahun pelepah daun dapat menyediakan $2.152 \mathrm{~kg}$ pelepah atau setara dengan 2,95 ekor sapi dengan berat badan $200 \mathrm{~kg}$.

Integrasi sawit-sapi merupakan usaha yang dilakukan untuk mengoptimalkan pemanfaatan lahan, peningkatan pendapatan, dan menjaga kualitas lingkungan (Sudaryanto dan Jamal, 2002). Produksi daging sapi di Provinsi Riau hingga saat ini baru mampu memenuhi sekitar 47\% kebutuhan (Dinas Peternakan dan Kesehatan Hewan Provinsi Riau, 2013), dan berpeluang untuk ditingkatkan melalui integrasi sawit-sapi. Daerah-daerah sentra sapi di Provinsi Riau meliputi Kabupaten Rokan Hulu, Indragiri Hilir, Kampar, Kuantan Singingi, dan Siak. Integrasi sawit-sapi di Provinsi Riau sudah mulai dilakukan melalui ujicoba pada beberapa lokasi, akan tetapi hasilnya belum maksimal. Hal ini disebabkan antara lain kurangnya pengetahuan petani tentang teknologi dan penerapannya.

Keberhasilan implementasi model pertanian bioindustri sawit-sapi di Provinsi Riau tergantung pada 4 (empat) faktor yakni (a) adanya program Pemda, (b) tersedianya teknologi, (c) tersedianya sarana dan prasarana pendukung, dan (d) tersedianya SDM yang handal. Pemda lingkup Provinsi Riau telah mencoba mengimplementasikan 8 (delapan) unit percontohan integrasi sawit-sapi, tetapi kinerja program tersebut belum memadai karena keterbatasan pengetahuan petani dalam menerapkan teknologi (Dinas Peternakan dan Kesehatan Hewan Provinsi Riau, 2013). Oleh 
karena itu diperlukan dukungan inovasi teknologi berupa perbaikan manajemen produksi sawit, manajemen produksi daging sapi, manajemen produksi ikan, manajemen produksi sayur organik, pemanfaatan limbah untuk pupuk organik, biogas.

Tujuan dari kegiatan ini adalah meningkatkan pendapatan petani sawit-sapi diwilayah kajian dan meningkatkan efisiensi uasahatani sapi-sawit.

\section{METODOLOGI}

\section{A. Pendekatan}

Kegiatan dilaksanakan, Kecamatan Tapung, Kabupaten Kampar, Provinsi Riau mulai bulan Januari - Desember 2018. Petani yang menjadi kooperator adalah petani yang memiliki lahan sawit dan memelihara sapi, menggunakan kandang komunal. Pendekatan yang digunakan meliputi pendekatan produktivitas, pendapatan dan

lingkungan.

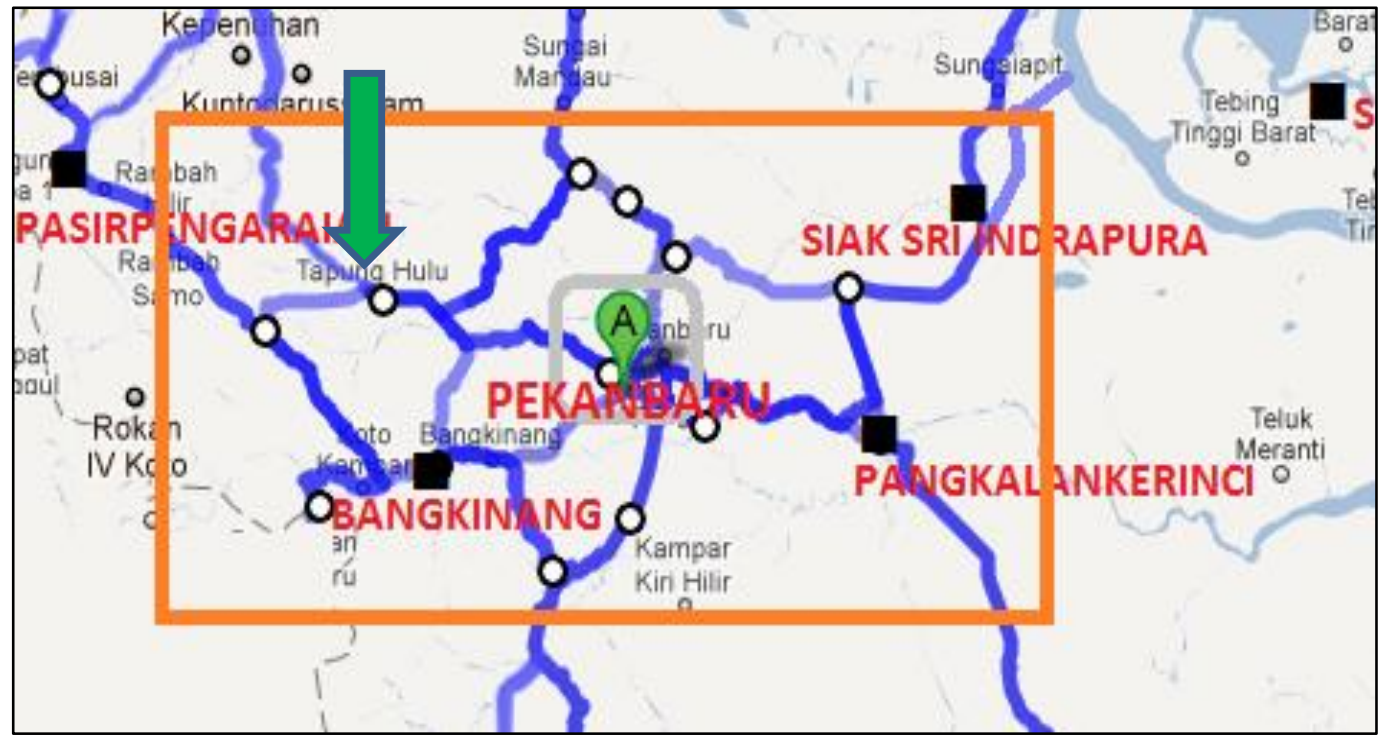

Gambar 1. Peta Lokasi Kegiatan Model Bio Industri

Peningkatan Pendapatan petani komodtas sawit dan sapi yaitu dengan cara memanfaatkan limbah sawit, berupa pelepah dan tandan kosong sawit sebagai pakan ternak, kompos dan asap cair yang dapat digunakan sebagai koagulasi karet, pestisida alami, sementara limbah ternak dapat dimanfaatkan sebagai bio energy berupa gas, pupuk padat, pupuk cair dan sebagai pestisida alami.

\section{B. Ruang Lingkup Kegiatan}

Ruang lingkup kegiatan meliputi koordinasi dengan Instansi terkait, mencari data primer yang diambil dari BPP kecamatan Tapung, pengenalan teknologi memanfaatkan limbah sawit, berupa pelepah sebagai pakan ternak, dan tandan kosong sawit sebagai kompos dan asap cair. Asap cair dapat digunakan sebagai koagulasi karet, pestisida alami, kemudian melakukan pelatihan-pelatihan berupa inovasi teknologi yang sudah diperkenalkan. Tahap selanjutnya adalah diseminasi model pertanian bioindustri terpadu sawit-sapi kepada stakeholder terkait seperti Pemda, petani dan peternak serta pelaku usaha. Kegiatan ini dilaksanakan setelah semua inovasi teknologi yang diterapkan menunjukkan kinerja yang baik dan secara teknis dan ekonomis menguntungkan, terakhir kegiatan ini dilkakukan pembuatan rekomendasi sebagai acuan program dinas perkebunan dan peternakan Kabupaten Kampar. 


\section{Metode Pelaksanaan}

Untuk lebih aplikasinya kegiatan yang akan dilakukan maka disusun metode pelaksanaannya.

\section{Informasi kondisi wilayah model pertanian bioindutri}

Untuk mencari informasi diwilayah kegiatan model pertanian bioindustri ini dalah dengan cara pengambilan data primer dari BPP dan juga menggali informasi dari aparat setempat, masyarakat dan petani koperator, data tersebut langsung dinarasikan untuk ditampilkan dalam makalah ini, kemudian setelah diketahui kondisi ini baru dicari dan ditentukan model yang tepat untuk pelaksanakan kegiatan ini dilapangan.

\section{Teknologi inovatif Model Pertanian Bio Industri}

Teknologi inovatif yang dikembangan di wilayah ini adalah berupa Pemanfaatan pelepah sawit sebagai Pakan ternak, Daun Pelepah tanaman kelapa sawit yang akan dijadikan pakan dicacah sampai halus terlebih dahulu, kemudian dicampur dengan Bungkil Inti sawit, Pelepah sawit, Solid, Rumput unggul, Bungkil kedele, Molases, Ultra mineral, kalsium (tepung kerang), urea dan garam. Dan kemudian difermentasi selama 21 hari.

Pemanfaatan tandan kosong sawit sebagai pupuk organic dan asap cair, Tandan kosong sawit (Tankos) yang dihasilkan sebanyak $23 \%$ dari produksi sawit dapat dimanfaatkan sebagai bahan campuran kompos, sebelum digunakan tankos dicacah dengan mesin pencacah sepanjang 3-5 cm, kemudian dicampur dan diaduk dengan decomposer, untuk meningkatkan unsur hara yang dibutuhkan oleh tanaman tankos dapat dicampur dengan kotoran ternak, sementara untuk pembuatan asap cair tankos dari pabrik dijemur dan kemudian dibakar dengan menggunakan alat pembakar berupa pirolisis, kemudian asap cairnya didistilasi sehingga menghasilkan asap cair yang berkualitas.

Pemanfaatan limbah ternak sebagai bio energi, pembuatan pupuk organik padat. Pupuk organik cair dan pestisida alami. Limbah ternak berupa padat dan cair yang selama ini tidak dimanfaatkan oleh peternak, yang padat di bakar,sementara yang cair dibuang begitu saja pada hal kedua limbah ini bisa menghasilkan uang masuk bagi petani, peternak, untuk itu kedua limbah tersebut diolah untuk dijadikan pupuk organic padat dan pupuk organik cair juga bisa digunakan untuk pestisida alami.

\section{HASIL DAN PEMBAHASAN}

\section{A. Geografis dan jumlah Penduduk Kecamatan Tapung}

Kecamatan Tapung merupakan salah satu kecamatan yang terletak di Kabupaten Kampar dengan luas keseluruhannya adalah $\pm 739,21 \mathrm{~km}^{2}$ atau 73.921 ha, jumlah desa sebanyak 25 desa, dengan pusat kota kecamatan di desa Patapahan (BPS 2015). Kecamatan Tapung berbatasan dengan: sebelah utara berbatasan dengan Kecamatan Tapung Hulu dan Tapung Hilir. Sebelah Timur berbatasan dengan Kota Pekanbaru, sebelah selatan berbatasan dengan Kecamatan Tambang, kecamatan Kampar, Kecamatan Rumbio Jaya, Kecamatan Kampar Utara, kecamatan Kampar Timur, kecamatan Salo dan Kecamatan Bangkinang seberang, sebelah Barat berbatasan dengan Tapung Hulu dan Rokan Hulu.

Jumlah Penduduk kecamatan Tapung adalah sebanyak 102.001 jiwa, terdiri dari lakilaki sebanyak 53.083 dan perempuan sebanyak 48.918 jiwa dengan kepadatan penduduk 137 jiwa/km² (BPS, 2014).

Menurut BPS (2017), bahwa di Kecamatan Tapung memiliki lahan sawit seluas 34.102 ha dengan jumlah petani sebanyak 18.151 kepala keluarga, berarti rata-rata satu kepala keluarga mengelola tanaman sawit seluas hampir kurang lebih 2 hektar. Petani di Kecamatan Tapung didominasi oleh etnis jawa yang mulai mengelola tanaman sawit semenjak tahun 1992, dengan luasan masing-masing 2 hektar termasuk lahan pekarangan. Para petani di kecamatan Tapung sangat aktif sehingga pada tahun 2011 pemerintah provinsi Riau melalui dinas Peternakan Provinsi Riau memberikan bantuan sebanyak 2 ekor dan pada tahun 2016. Dinas Peternakan kembali memberikan bantuan sebanyak 25 ekor ke kelompok tani puja kesuma dan 1 buah coper untuk alat pencacah pelepah sawit, namun petani 
belum bisa menggunakan alat yang dibantu oleh dinas sehingga untuk mencari makan ternaknya petani masih mencari rumput alam, waktu yang dibutuhkan dalam mencarui rumput selama 2 jam untuk 2 ekor ternak. Pada tahun 2015 BPTP Riau melalui kegiatan Bio Indutri memperkenalkan cara pembuatan pakan ternak dari pelepah tanaman sawit. Sampai saat ini pembuatan pakan komplete feed tetap dilakukan setiap minggu dengan kapasitas 3-4 ton untuk memenuhi kebutuhan ternak sapi sebanyak 50 ekor, pembuatan pakan komplete yang dilakukan saat ini tidak menggunakan pelepah tanaman sawit karena mesin kondisi mesin pencacah tidak dapat menghaluskan lidi tanaman sawit dikuatirkan tersangkut dikerongkongan sapi, namun demikian sebagai pengganti pelepah sawit digunakan rumput gajah sebanyak $65 \%$, Bungkil inti sawit sebanyak $15 \%$, dedak $10 \%$ Probiotik $1 \%$, molases $8,9 \%$ dan mineral sebanyak $0,1 \%$.

\section{B. Model Pertanian Bioindustri}

Model pertanian bioindustri sapi-sawit Kecamatan Tapung, Kabupaten Kampar menerapkan sistem simbiosis mutulalisme antara tanaman sawit dan sapi (Gambar 2). Tanaman sawit menghasilkan limbah berupa pelepah sawit dan tankos, pelepah sawit dapat dimanfaatkan sebagai bahan pembuat pakan ternak atau komplete feed, tankos dapat dibuat asap cair dan asap cair disinyalir dapat dimanfaatkan untuk obat kutu dan lalat yang hinggap di ternak, sementara limbah ternak dapat dimanfaatkan untuk penyubur tanaman sawit dari hasil survey BPTP Riau 2018 dilaporkan bahwa penggunaan bahan limbah dari ternak yang sudah difermentasi menjadi kompos dapat meningkatkan efisiensi penggunaan pupuk kimia sebanyak $50 \%$ dari 20 $\mathrm{kg}$ ure/ha, $200 \mathrm{~kg} \mathrm{SP} 36 / \mathrm{ha}$ dan $200 \mathrm{~kg} \mathrm{KCl} / \mathrm{ha}$ menjadi tanpa urea, $100 \mathrm{~kg}$ SP36 dan $100 \mathrm{~kg}$ $\mathrm{KCl} / \mathrm{ha}$.

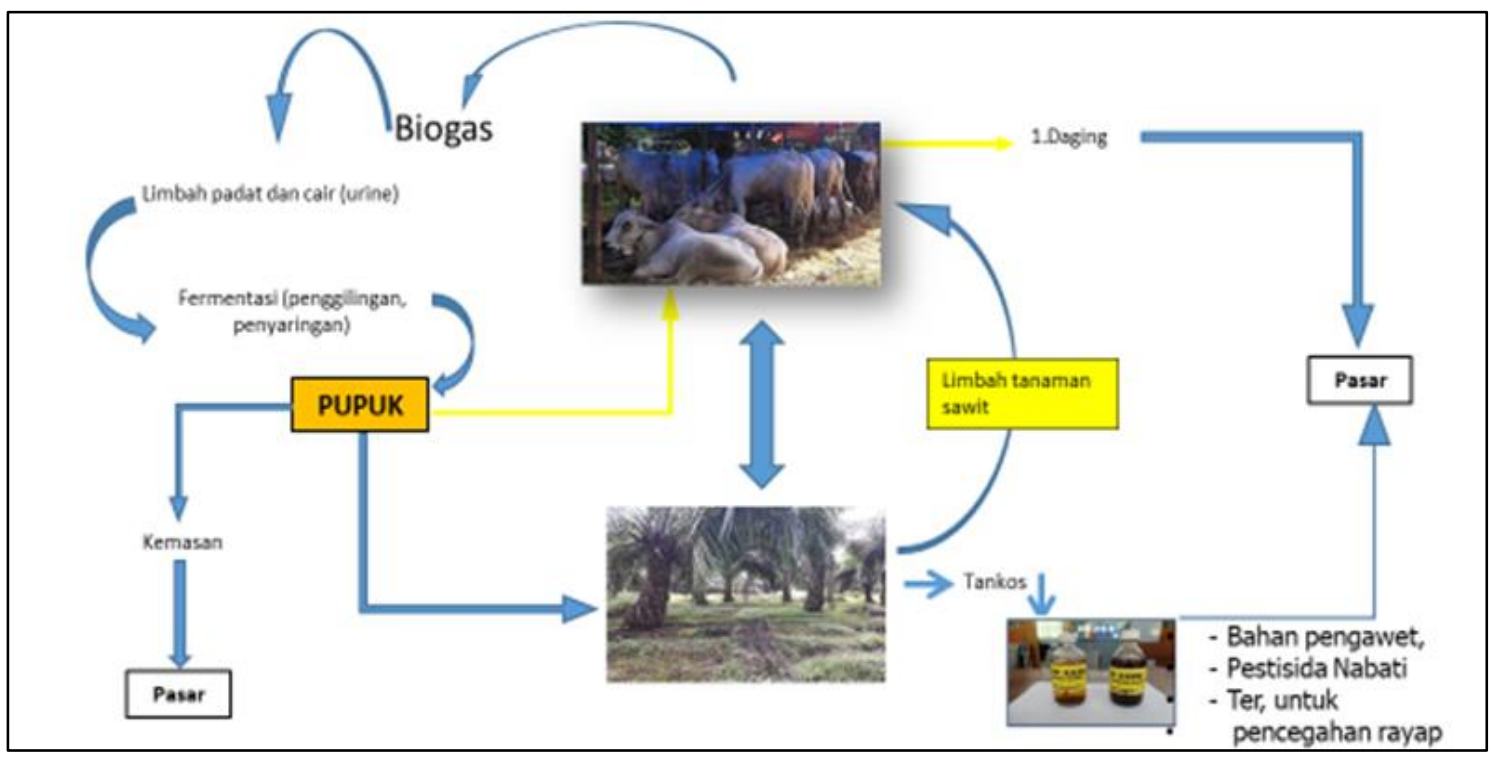

Gambar 2. Model Bio industry sapi-sawit di Provinsi Riau

\section{Teknologi inovatif Model Pertanian Bio Industri}

Pemanfaatan produk pertanian untuk konsumsi (pangan, pakan, bahan baku industri dan energi) secara berkelanjutan hanya dapat terwujud jika pemanfaatan tersebut tidak mengabaikan kesehatan lahan (Kementerian Pertanian, 2014). Model Pertanian bioindustri sapi-sawit yang diterapkan di Kecamatan Tapung, berdasarkan ilmu pengetahuan dan teknologi yang memungkinkan keseluruhan komponen biomassa dengan cermat dapat dimanfaatkan untuk konsumsi sementara mineral dan bahan-bahan organik yang esensial bagi tanaman dapat didaur-ulang sebagai , bioenergy, kompos, pupuk cair organic yang merupakan konsep dari pertanian berkelanjutan. Pengertian 
pertanian berkelanjutan seperti disebutkan di atas mengandung makna meningkatkann efisiensi penggunaan nutrisi (increasing nutrient use efficiency) dan meminimalkan penggunaan input eksternal khususnya bahan dan energi fosil di sektor pertanian (net-zero consumption of fossil energy in agricultural sector. Untuk menjaga lingkungan berkelanjutan yang diwujudkan melalui pemeliharaan ekosistem agar tetap berfungsi baik sebagai 'sumber' dari input maupun sebagai 'resapan' bagi limbah, terlebih dahulu perlu dicermati dan dipahami pengertian mendasar dari ekosistem seperti definisi dan ciri ekosistem berikut ini. Ekosistem adalah sistem ekologi, saling ketergantungan komunitas makhluk hidup yang berperan mendaur ulang zat sewaktu energi mengalir melalui suatu luasan tertentu yaitu lingkungan alam di sekitarnya. Ciri utama dari suatu ekosistem adalah: ekosistem terdiri dari organisme hidup (biotik) dan bagian tidak hidup (abiotik); energi mengalir (bertransformasi) melalui organisme di dalam (Manurung, 2014).

Pemberian daun dan pelepah sawit pada ternak melalui perlakuan fisik terlebih dahulu berupa perajangan menggunakan mesin chopper, sehingga didapatkan daun dan pelepah sawit berbentuk halus. Tujuannya adalah agar ternak dapat lebih mudah dalam mengkonsumsi kedua bahan tersebut sehingga diharapkan tingkat konsumsi dan kecernaannya meningkat. Kecernaan bahan pakan dapat meningkat dengan semakin luasnya permukaan bahan yang dapat diakses oleh mikroba rumen untuk membentuk koloni dan selanjutnya mendegradasi bahan pakan. Pemanfaatan limbah sawit terutama daun dan pelepah sawit, sebagai pakan ternak di Propinsi Riau khususnya di Kecamatan Tapung sangat sesuai diterapkan dengan adanya perkebunan kelapa sawit yang tersebar hampir disemua kabupaten yang mencapai $1 / 3$ dari total luas perkebunan kelapa sawit yang ada di Indonesia. Diharapkan dengan ketersediaan pakan asal limbah kelapa sawit dapat meningkatkan jumlah populasi dan produktivitas ternak sapi. Prediksi sementara menunjukkan bahwa untuk swasembada daging di Provinsi Riau diperlukan 39.275 ST per tahun (Dinas Peternakan dan Kesehatan Hewan Riau, 2013).
Provinsi Riau akan mampu mencapai sawasembada daging sapi bilamana program integrasi sapi-sawit dapat diwujudkan. Teknologi inovatif model pertanian bioindustri sapi-sawit Kecamatan, Tapung Kabupaten Kampar khususnya untuk turunan tanaman sawit yang sudah dilakukan adalah pembuatan komplete feed, pembuatan pupuk organic dari tankos dan pembuatan asap cair dari tankos. Pembuatan komplete feed untuk usaha peternakan sangat membantu peternak dari kelompok tani Focus hasil gemilang. Karena dapat mengefisiensikan tenaga mereka dalam dalam pencarian rumput alam, biasanya waktu yang dibutuhkan untuk mencari rumput alam untuk memelihara 1 ekor sapi adalah selama 2 jam, karena jarak tempuh dari rumah ke padang rumput cukup jauh, sementara bila mereka membuat pakan komplete feed ini peternak hanya meluangkan waktu untuk mengumpulkan pelepah sawit, kemudian mencacah dan mencampur dengan beberapa bahan seperti dedak, bungkil inti sawit, dan starbio kemudian difermentasi, pakan fermentasi ini bisa disimpan lebih dari 6 bulan. Kelompok ini memiliki ternak sapi sebanyak 8 ekor, bila 1 ekor ternak butuh 8-10 kg komplete feed maka dalam 1 hari peternak hanya menyediakan pakan sebanya $64-80 \mathrm{~kg}$. dan bila hanya menggunakan hijauan petani focus hasil gemilang membutuhkan hijauan sebanyak 40-50 kg perhari untuk 1 ekor sapi, maka dalam 1 hari butuh pakan hijauan sebanyak 320- $400 \mathrm{~kg} / \mathrm{hari}$.

Pembuatan pupuk organik dari tankos dilakukan untuk mengurangi kebutuhan pupuk anorganik. Tankos setelah dicacah, lalu dicampur dengan decomposer mikroorganisme dan pupuk kandang, kemudian difermentasi selama 21 hari, pembuatan kompos yang dilakukan di Kecamatan Tapung dikelola oleh Kelompok tani Fokus hasil gemilang, dari 8 ekor sapi, kelompok ini menghasilkan kotoran sebanyak $48 \mathrm{~kg}-64 \mathrm{~kg}$ dalam satu hari maka dalam satu bulan sudah dapat menghasilkan kotoran sapi sebanyak $1.44 \mathrm{t}$, dari 1.344 ton pupuk kandang menghasilkan kompos sebanyak 1 ton dari kotoran sapi, dan bila ditambah dengan tandan kosong sawit sebanyak $500 \mathrm{~kg}$, maka dikelompok ini dapat menghasilkan kompos sebanyak $1,500 \mathrm{~kg} / \mathrm{bulan}$, dari hasil pembuatan kompos tersebut petani di kelompok 
tani focus hasil gemilang dapat tambahan pendapatan sebanyak Rp.3000.000,- dengan harga kompos Rp.2000,-/kg

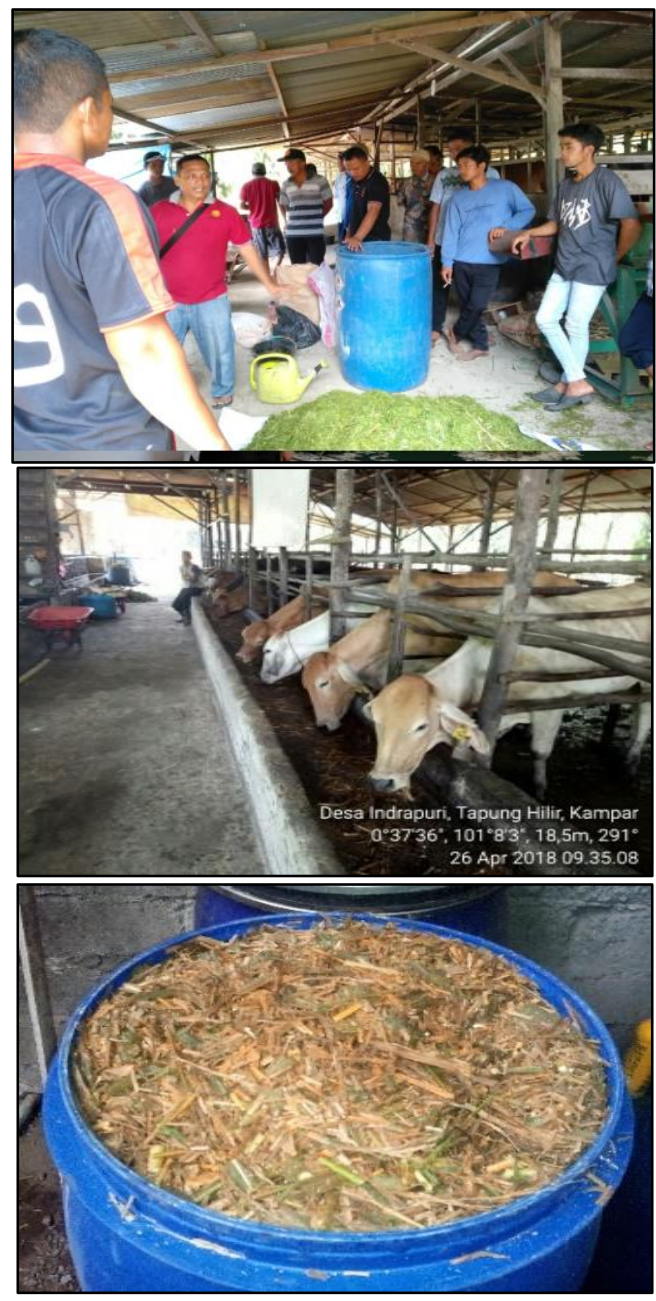

Gambar 3. Proses pembuatan komple feed.

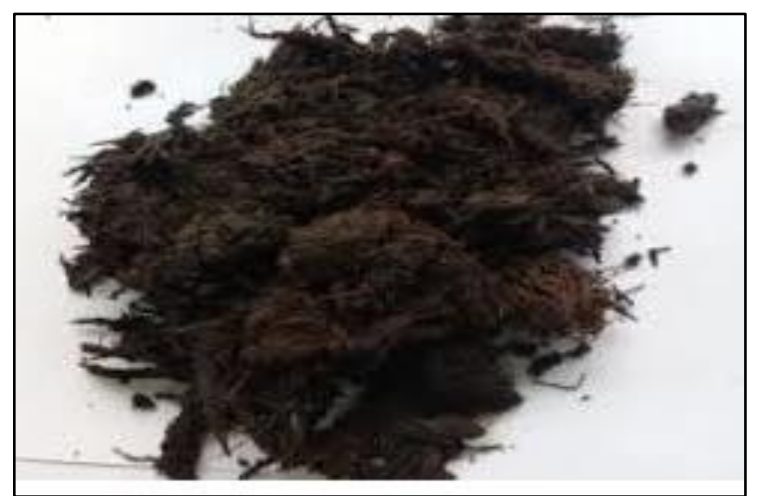

Gambar 4. Kompos campuran tandan kosong sawit dan kotoran sapi

Untuk meningkatkan nilai jual dari kompos yang dibuat petani koperator, bahan harus dilakukan analisis, kemudian kompos dikemas dalam karung. Pembuatan pupuk cair organic yang berasal dari urine sapi bertujuan untukmenguramgi penggunaan pupuk anorganik, berdasarkan hasil uji coba di tanaman sawit bahwa penggunaan urine sapi yang dibarengi dengan penggunaan pupuk kompos dapat meningkatkan efisiensi penggunaan bahan anorganik sebanyak 50\% (Komunikasi Pribadi, 2017). Pembuatan asap cair dilakukan guna untuk mengurangi polusi bertumpuknya tandan kosong di pabrik kelapa sawit, karena sekitar $23 \%$ dari produksi kelapa sawit adalah tandan kosong sawit (Lembaga Riset Perkebunan Indonesia, 2003). Asap cair menurut Basri (2010) bermanfaat untuk meningkatkan kualitas tanah dan menetralisir asam tanah, membunuh hama tanaman dan mengontrol pertumbuhan tanaman, pengusir serangga, mempercepat pertumbuhan pada akar, batang, umbi, daun, bunga, dan buah, sebagai penggumpal lateks atau getah karet sebagai pengawet makanan.

\section{Kinerja Bioindustri untuk tanaman sawit}

Untuk membuktikan efektivitas pupuk padat dan cair yang dibuat di Bioindustri ini dilakukan uji coba ke tanaman sawit milik petani dengan catatan petani mau bekerja sama dengan peneliti. Perbaikan produktivitas tanaman sawit milik petani koperator dilakukan dengan cara memberikan pupuk kompos dan pupuk cair organik yang dihasilkan di kegiatan model Pertanian Bioindustri. Pupuk dan bio urine ini diberikan kepada petani non koperator dengan luasan 1 hektar.

\section{Produksi Kelapa sawit}

Pengamatan yang dilakukan pada tanaman kelapa sawit meliputi pengamatan produktivitas tanaman kelapa sawit. Pengamatan dilakukan setelah 6 bulan aplikasi pemupukan dilakukan. Pengamatan produktivitas tanaman kelapa sawit bertujuan untuk mengetahui perkembangan hasil produktivitas tanaman kelapa sawit yang telah 
diaplikasi dengan pupuk organik padat dan pupuk organik cair, dengan parameter yang diamati meliputi jumlah tanaman yang dipanen, rata-rata bobot segar/ha/bulan, produktivitas ha/bulan. Hasil pengamatan produktivitas tanaman kelapa sawit memperlihatkan bahwa dari 4 perlakuan yang diuji penggunaan POC (5 liter/pohon) yang dikombinasikan dengan penggunaan POP (5 $\mathrm{kg} /$ pohon menghasilkan produksi tandan buah segar (TBS) lebih tinggi $(2.580 .8 \mathrm{~kg} / \mathrm{ha} / \mathrm{bulan})$ dibanding tanaman sawit yang dipupuk POC (10 liter/pohon/6 bulan) dengan POP $(10 \mathrm{~kg} /$ pohon $/ 6$ bulan) Sementara penggunaan pupuk an organik saja hanya menghasilkan TBS sebanyak 1879,8 $\mathrm{kg} / \mathrm{ha} /$ bulan. Lebih tingginya produksi tandan buah segar kelapa sawit pada penggunaan POC + POP ini disebabkan oleh kondisi tanah yang lebih gembur dan lebih suburnya lahan di area sawit tersebut.

Tabel 1. Rataan Produksi Tandan buah segar (TBS) Kelapa sawit pada penggunaan POC dan POP.

\begin{tabular}{cccc}
\hline Perlakuan & $\begin{array}{c}\text { Rataan Pohon } \\
\text { Dipanen/ha/bulan } \\
\text { (pohon) }\end{array}$ & $\begin{array}{c}\text { Rataan Bobot } \\
\text { TBS/pohon } / \text { bln } \\
(\mathrm{Kg})\end{array}$ & $\begin{array}{c}\text { Bobot TBS ha/bln } \\
(\mathrm{Kg})\end{array}$ \\
\hline A & 111,33 & 16,88 & 1879,8 \\
B & 97,08 & 16,88 & 1638,9 \\
C & 114,2 & 18,91 & 2159,5 \\
D & 125,6 & 20,54 & 2580,8 \\
\hline
\end{tabular}

Keterangan A : Kontrol . B $10 \mathrm{~kg}$ Pupuk Organik padat, 0 pupuk cair, C 0 pupuk padat, 10 liter pupuk cair d. $5 \mathrm{~kg}$ pupuk Padat dan $5 \mathrm{~kg}$ pupuk cair.

\section{Penggunaan sarana produksi Kegiatan}

Perhitungan ini hanya untuk mengetahui biaya input produksi berupa pembelian pupuk organik dan anorganik selama dilakukan kegiatan Bio industry di Kecamatan Tapung, Kabupaten Kampar. Biaya yang dikeluarkan oleh petani sawit untuk memproduksi tandan buah segar (TBS) kelapa dapat dilihat pada Tabel 2. Biaya penggunaan sarana produksi kegiatan penggunaan POC dan POP tertingi pada pembelian pupuk $\mathrm{KCl}$, yaitu $\mathrm{Rp}$. 2.380.000,kemudian diikuti oleh biaya pembelian Urea dan TSP masing-masing Rp. 1,768.000 dan Rp. 1.519.000 serta kiserit sebanyak Rp. 1.175.000,yang diberikan setiap 6 bulan. Total biaya produksi untuk masing-masing perlakuan adalah Kontrol (A). Rp. 5.667.000,- $10 \mathrm{~kg}$ pupuk padat,
0 kg pupuk cair (B) Rp.6.347.000,- 0 pupuk padat, 10 penggunaan cair ( C). Rp.8.387.000 dan Penggunaan $5 \mathrm{~kg}$ pupuk padat dan 5 liter cair (D). Rp. 8.047.000,- untuk biaya tenaga kerja dalam laporan ini tidak dihitung, karena saat diwawancarai petani merasa ragu untuk menjawabnya dan kadang-kadang mereka lupa dan tidak mengetahui. Kalau dilihat biaya yang dikeluarkan oleh petani pada perlakuan D lebih besar dibanding dengan perlakukan lainnya, karena perlakukan D harus mengeluarkan biaya pembelian bio urine dan pupuk kompos yang dihasilkan oleh petani pembuat kompos dan petani pembuat bio urine. Namun demikian saat panen pertama kelihatan produksi belum signifikan (Tabel 1), hanya selisih $421.3 \mathrm{~kg}-$ $701 \mathrm{~kg}$ disbanding perlakuan lainnya. 
Tabel 2. Penggunaan produk bioindustri untuk tanaman sawit

\begin{tabular}{|c|c|c|c|c|c|c|c|c|}
\hline \multirow[t]{2}{*}{ Uraian } & \multicolumn{2}{|c|}{ Kontrol } & \multicolumn{2}{|c|}{$\begin{array}{l}10 \mathrm{~kg} \text { pupuk padat, } \\
0 \mathrm{~kg} \text { pupuk cair }\end{array}$} & \multicolumn{2}{|c|}{$\begin{array}{l}0 \text { pupuk padat, } 10 \\
\text { penggunaan cair }\end{array}$} & \multicolumn{2}{|c|}{$\begin{array}{c}\text { Penggunaan } 5 \mathrm{~kg} \\
\text { pupuk padat dan } 5 \text { liter } \\
\text { cair }\end{array}$} \\
\hline & Fisik & $\begin{array}{c}\text { Biaya } \\
\text { (Rp) }\end{array}$ & Fisik & Biaya (Rp) & Uraian & Perlakuan & Fisik & Biaya (Rp) \\
\hline \multicolumn{9}{|l|}{ Pupuk } \\
\hline Urea $(\mathrm{kg})$ & 272 & 1.768 .000 & 272 & 1.768 .000 & 272 & 1.768 .000 & 272 & 1.768 .000 \\
\hline $\mathrm{TSP}(\mathrm{Kg})$ & 217 & 1.519 .000 & 217 & 1.519 .000 & 217 & 1.519 .000 & 217 & 1.519 .000 \\
\hline $\mathrm{KCl}(\mathrm{Kg})$ & 340 & 2.380 .000 & 340 & 2.380 .000 & 340 & 2.380 .000 & 340 & 2.380 .000 \\
\hline Kiserit $(\mathrm{Kg})$ & 163,2 & 1.175 .000 & 163,2 & 1.175 .000 & 163,2 & 1.175 .000 & 163,2 & 1.175 .000 \\
\hline Kompos (kg) & 0 & 0 & 1360 & 680.000 & 0 & 0 & 680 & 340.000 \\
\hline Urine sapi (L) & 0 & 0 & & 0 & 1360 & 2.720 .000 & 680 & 1.360 .000 \\
\hline Jumlah & & 5.667 .000 & & 6.347 .000 & \multicolumn{2}{|r|}{8387.000} & \multicolumn{2}{|r|}{8.047 .000} \\
\hline \multicolumn{5}{|c|}{$\begin{array}{l}\text { 3. Penerimaan Petani } \\
\text { Penerimaan yang diperhitungkan dalam } \\
\text { pengkajian ini adalah hasil yang dicapai dari } \\
\text { setiap perlakuan kemudian dikalikan dengan } \\
\text { harga yang berlaku didaerah kajian. Sementara } \\
\text { pendapatan bersih adalah penerimaan dikurangi }\end{array}$} & \multicolumn{4}{|c|}{$\begin{array}{l}\text { dengan biaya yang dikeluarkan selama } 6 \text { bulan, } \\
\text { kemudian dirata-ratakan perbulan. Harga sawit di } \\
\text { wilayah pengkajian pada saat panen adalah Rp. } \\
1,200,- \text { Perlakuan } D \text { memperoleh keuntungan } \\
\text { ebih tinggi dibanding perlakukan lain } \\
\text { ainnya,akan tetapi R/C dan B/C ratio tertinggi } \\
\text { pada perlakuan A. }\end{array}$} \\
\hline \multicolumn{9}{|c|}{ Tabel 8. Penggunaan sarana produksi kegiatan } \\
\hline \multirow{2}{*}{\multicolumn{2}{|c|}{ Uraian }} & \multicolumn{5}{|c|}{ Perlakuan } & & \\
\hline & & \multicolumn{2}{|c|}{ A } & \multicolumn{2}{|c|}{ B } & \multicolumn{2}{|l|}{$\mathrm{C}$} & $\mathrm{D}$ \\
\hline \multicolumn{3}{|l|}{ Hasil } & \multicolumn{2}{|c|}{1879,8} & 638.900 & \multicolumn{2}{|c|}{$2.159,5$} & $2.580,8$ \\
\hline \multicolumn{3}{|l|}{ Penerimaan } & \multicolumn{2}{|c|}{2.255 .760} & 66.680 & 2.591 & & 3.096 .960 \\
\hline Biaya untuk 6 & & & 5.667. & & 47.000 & 8.387 & & 8.047 .000 \\
\hline Rata-rata biay & & & 944 & & 57.833 & 1,397 & & 1.341 .167 \\
\hline Pendapatan be & & & 1.311. & & 08.847 & 1.193 & & 1.755 .793 \\
\hline $\mathrm{R} / \mathrm{C}$ & & & & & 1,85 & & 85 & 2,31 \\
\hline $\mathrm{B} / \mathrm{C}$ & & & & & 0,86 & & 85 & 1,31 \\
\hline
\end{tabular}

Keterangan: Harga sawit Rp.1.200,-

\section{KESIMPULAN}

Model pertanian Bio Industri berbasis sapi-sawit di Provinsi Riau adalah merupakan hubungan simbiosis mutualisme antara tanaman sawit dan ternak, limbah sawit dapat dimanfaatkan oleh ternak, begitu juga sebaliknya limbah ternak dapat dimanfaatkan untuk sawit, pupuk organik yang dihasilkan dari kotoran ternak dapat mensubsitusi kebutuhan pupuk organik sebanyak $50 \%$.
Penerapan teknologi inovatif seperti pembuatan pakan komplete feed, dapat meingkatkan efeisensi tenaga kerja yang dicurahkan untuk pemeliharaan ternaknya, pembuatan kompos dari kotoran ternak dapat meningkatkan pendapatan petani sebanyak 3 juta perbulan, pengunaan mikroorganisme pada pemelihaaan ternak di Kecamtan Tapung dapat mengurangi polusi atau aroma kandang ternak yang tidak sedap.

Dampak dari kegiatan bioindustri terhadap tanam sawit milik petani adalah adanya 
peningkatan produktivitas dari $1879,8 \mathrm{~kg} / \mathrm{ha}$ menjadi $2580,80 \mathrm{~kg} / \mathrm{ha}$ atau meningkat sebanyak $37 \%$, dan petani mendapatkan tambahan pendapatan sebanyak Rp. 568,54 dalam 1 hektarnya perbulan.

\section{DAFTAR PUSTAKA}

Badan Pusat Statistik (BPS) Kabupaten Kampar. 2014.

Badan Pusat Statistik (BPS) Kabupaten Kampar. 2015.

Badan Pusat Statistik (BPS) kabupaten Kampar. 2017.

Basri AB, 2010. Manfaat Asap Cairuntuk Tanaman, SERAMBI PERTANIAN VOL. IV/ NO. 5/2010. ISSN 1907-7858. Banda Aceh

Biro Perencanaan. 2013. Konsep Strategi Induk Pembangunan Pertanian 2013-2045: Pertanian-Bioindustri Berkelanjutan: Solusi Pembangunan Indonesia Masa Depan. Sekretariat Jenderal, Kementerian Pertanian, Jakarta. $184 \mathrm{hlm}$.

Dinas Perikanan dan Kelautan Provinsi Riau. 2013. Data dan Informasi Perikanan dan Kelautan Provinsi Riau. 2013. Pekanbaru. $82 \mathrm{hlm}$.

Dinas Perkebunan Provinsi Riau. 2013. Data Statistik Perkebunan Provinsi Riau. Dinas Perkebunan Provinsi Riau. Pekanbaru. 172 hlm.

Dinas Peternakan dan Kesehatan Hewan Provinsi Riau. 2009. Statistik Ternak. Pekanbaru. $23 \mathrm{hlm}$.

Ditjenbun. 2017. Perkembangan terkini program peremajaan kelapa sawit nasional. Kementerian pertanian direktorat jenderal perkebunan. Disampaikan pada acara. Pertemuan kelapa sawit pada acara pertemuan teknis kelapa sawit.

Kementerian Pertanian. 2014. Strategi Induk Pembangunan Pertanian 2015-2045: Pertanian-Bioindustri Berkelanjutan, Solusi Pembangunan Indonesia Masa Depan. Biro Perencanaan, Sekretariat Jenderal Kementerian Pertanian, Jakarta.

Masganti. 2013. Teknologi Inovatif Pengelolaan Lahan Suboptimal Gambut dan Sulfat
Masam untuk Peningkatan Produksi Tanaman Pangan. Orasi Pengukuhan Profesor Riset Bidang Kesuburan Tanah dan Biologi Tanah. Badan Penelitian dan Pengembangan Pertanian. Kementerian Pertanian-LIPI. IAARD Press. $60 \mathrm{hlm}$.

Parulian T.S, 2009. Efek Pelepah Daun Kelapa Sawit dan Limbah Industrinya Sebagai Pakan terhadap Pertumbuhan Sapi Peranakan Ongole Pada Fase Pertumbuhan. (http://repository. usu.ac.id/handle/123456789/7623). 3 April 2014.

Sudaryanto, T. dan E. Jamal. 2002. Pengembangan agribisnis peternakan melalui pendekatan corporate farming untuk mendukung ketahanan pangan nasional. Dalam Monograf Series No. 22. Sudaryanto, T., I.W. Rusastra, A. Syam dan M. Ariani (Eds.) 2002. Analisis Kebijaksanaan Pendekatan Pembangunan dan Kebijaksanaan Pengembangan Agribisnis) Pusat Penelitian dan Pengembangan Sosial Ekonomi Pertanian Badan Litbang Pertanian.

Manurung, R. 2014. Pengembangan sistem pertanian-bioindustri berkelanjutan peluang dan tantangannya. Prosiding Seminar Hasil Penelitian Tanaman Aneka Kacang dan Umbi 2014. file:///D:/referensi/3245_Manurung1.referensi\%20bio\%20industri.pdf

Lembaga Riset Perkebunan Indonesia. 2003. Inovasi Teknologi Kompos Produk Samping Kelapa Sawit. Prosiding Lokakarya Nasional Sistem Integrasi Kelapa Sawit-Sapi: p. 67-74. Bengkulu 910 September 2003. 